\title{
A clinical study of laparoscopic versus open umbilical hernia repair
}

\author{
Abhinava D.M ${ }^{1}$, Shashidhara Naik $C^{2}$, Seshagiri Rao $K^{3}$, Santhosh C.S $^{4}$, Mallikarjuna N Manangi ${ }^{5}$, Niranjan \\ Nagaraj ${ }^{6}$
}

${ }^{1}$ Dr. Abhinava D.M., ${ }^{2}$ Dr. Shashidhar Naik C, ${ }^{3}$ Dr. Seshagiri Rao K, ${ }^{4}$ Dr. Santhosh C.S., ${ }^{5}$ Dr. Mallikarjuna N Manangi, all are authors affiliated with Department of Surgery, Victoria Hospital, Bangalore Medical College and Research Institute, Bangalore, India, ${ }^{6}$ Dr. Niranjan Nagaraj, Department of Pediatrics, SP Medical College, Bikaner, Rajasthan, India.

Address for Correspondence: Dr. Shashidhar Naik C, Department of Surgery, Victoria Hospital, Bangalore Medical College and Research Institute, Bangalore, India. Email: cshashinaik@gmail.com

\begin{abstract}
Background: Umbilical Hernia is one of the most common surgical problems. Since the prosthetic repair has become the standard of practice for inguinal hernia management, the same has been adapted for Umbilical hernia management with better outcome. There is still debate going on regarding the better surgical approach. There are very few prospective studies comparing the laparoscopic and open method of Umbilical hernia mesh repair. This study compared the short term outcomes following laparoscopic versus open mesh repair of Umbilical hernia. Methods: Patients who underwent Umbilical hernia repair at Victoria hospital, Bengaluru between July 2015 to January 2017 were studied. Patients were divided into two groups, those who underwent Laparoscopic repair were considered into "group A" and those who underwent Open repair were considered into "group B". Both the groups were compared with respect to Duration of surgery, Use of Drains, complications like wound infection, seroma, and haematoma, Return to normal activity, Duration of hospital stay.Results:A total of 96 patients underwent umbilical hernia repair out of which 88 were included as 8 patients underwent primary suture repairs. Out of 88 patients 49(55.68\%) patients underwent Laparoscopic mesh repair [Group A] and 39 (44.32\%) patients underwent open mesh repair. Duration of surgery is relatively less in Group B, Use of Drains, Complications like wound infection, seroma and haematoma is significantly less in Group A, Duration of hospital stay is relatively less in Group A, Return to normal activity is faster in Group A. Conclusion: Laparoscopic umbilical hernia repair is a safe and effective technique. Laparoscopic mesh repair required in shorter duration of surgery, less use of postoperative drains, faster return to normal activity and less complications rate, shorter hospital stay.
\end{abstract}

Keywords: Umbilical hernia, Laparoscopic mesh repair, Open mesh repair.

\section{Introduction}

Umbilical Hernia is one of the most common surgical problems encountered in day to day practice. Umbilical hernias occur at the umbilical ring and may be present at birth or develop later in life. Umbilical hernias are present in approximately $10 \%$ of all newborns and are more common in premature infants. Most congenital umbilical hernias close spontaneously by 5 years if closure does not occur elective surgical repair is usually advised. Adults with small asymptomatic umbilical hernias should be followed clinically. Surgical treatment is offered if a hernia is observed to enlarge or is associated with symptoms, or if incarceration occurs. Surgical treatment consists of primary sutured repair or placement of prosthetic mesh for larger defects $(>2 \mathrm{cms})$ using open or

Manuscript Received: $10^{\text {th }}$ December 2017

Reviewed: $20^{\text {th }}$ December 2017

Author Corrected: $26^{\text {th }}$ December 2017

Accepted for Publication: $31^{\text {st }}$ December 2017 laparoscopic methods [1]. The technique described by Mayo in 1901 is the classic method for umbilical hernia repair [2], consisting of "vest-over-pants" imbrication of the superior and inferior aponeurotic segments. The technique is not frequently used nowadays. A primary suture repair for ventral or incisional hernias has recurrence rates of $25 \%$ and $52 \%$ for fascial defects smaller and larger than $4 \mathrm{~cm}$, respectively $[3,4]$.

The use of a variety of mesh materials for the repair of these hernias has resulted in a decreased recurrence rate when compared with that in primary suture closure $[5,6]$. Further research into the optimal surgeryof the Umbilical hernia repair lead surgeons to start practicing Laparoscopic mesh repair as there is an increasing evidence that laparoscopic repair of Umbilical hernia is superior to open mesh repair regarding operative and 


\section{Original Research Article}

postoperative complications, postoperative pain and overall morbidity and mortality[7]. The purpose of this study was to prospectively review all patients who underwent umbilical hernia repair and compare results of laparoscopic and open techniques, with emphasis on Duration of surgery, Use of Drains, postoperative pain, complicationslike wound infection, seroma, and haematoma, Return to normal activity, Duration of hospital stay.

\section{Material and Methods}

Type of study and place of study: A prospective study of all umbilical hernia repairs performed on patients who underwent Umbilical hernia repair at Victoria hospital, Bengaluru between July 2015 to June 2016 were studied.

Study subjects: Patients were divided into two groups, those who underwent Laparoscopic repair were considered into "group A" and those who underwent Open repair were considered into "group B". Both the groups were compared with respect to Duration of surgery, Use of Drains, complications like wound infection, seroma, and haematoma, Return to normal activity, Duration of hospital stay.

Inclusion and exclusion criteria: A single dose of a third generation cephalosporin was administered one hour induction of the anaesthesia. General anaesthesia was used in all patients who underwent Laparoscopic repair; spinal anaesthesia and sedation or epidural anaesthesia were used in patients who underwent open umbilical hernia repair, few patients who underwent open hernia repair chose general anaesthesia over spinal anaesthesia. The surgical technique was chosen on a patient-by-patient basis using the surgeons' judgment. Factors that influenced the decision to use the open technique consisted of age and history of previous multiple hernia repairs. Contraindications for laparoscopic repair included coagulopathy and severe cardiopulmonary disease.
Surgical technique: In the open hernia mesh repair technique, the mesh was placed preperitoneal layer after creating the space. It consisted of a wide dissection of tissue to allow a mesh overlap of $3 \mathrm{~cm}-5 \mathrm{~cm}$ beyond the outer border of the fascial defect. The mesh was fixed using interrupted long-term absorbable sutures at $1-\mathrm{cm}$ intervals. The mesh material used for the repair was either polypropylene. Drains were placed after any repair of a defect that required extended subcutaneous tissue dissection that resulted in bleeding or creation of a dead space.

Laparoscopic repair was performed after creating enough pnemoperitoneum briefly, after the laparoscope is used for inspection of the abdominal cavity, two 5-mm trocars are placed as far away as possible from the hernia defect. The hernia contents are reduced by blunt and sharp dissection with judicious use of electric cautery or harmonic arc. The mesh is measured with the abdomen deflated, allowing for at least a $3 \mathrm{~cm}$ to $5 \mathrm{~cm}$ overlap beyond the borders of the fascial defect and is fixed with tacks and full thickness sutures using non absorbable suture material or the tacks are placed every centimeter, and the full thickness sutures are placed every $3 \mathrm{~cm}$ to $5 \mathrm{~cm}$. The mesh materials used for the repair were vipro dual mesh.

Patients were evaluated till the day of discharge after surgery. Complications were recorded in clinical case sheets. All infections requiring antibiotic therapy were included. The results were compared with respect to Duration of surgery, Use of Drains, complications like wound infection, seroma, and haematoma, Return to normal activity, Duration of hospital stay.

Statistical analysis: All the collected data was tabulated. Statistical analysis was done by student $t$-test and $P$ values were calculated. The difference is considered statistically significant, whenever $\mathrm{p} \leq 0.05$ at all-time points measured. The statistical software used for analysis was SPSS.V. 15.0 .

\section{Results}

A total of 96 patients underwent umbilical hernia repair Victoria hospital, Bengaluru between July 2015 to January 2017 . Out of these 8 are excluded as they underwent primary suture repair. 88 cases were included in the studies that underwent mesh repair. Demographic data of these patients are tabulated in Table 1, mean age of the patients was 42.7 years.

There were 59(67.05\%) males and 29 (32.95\%) females. Patients were divided into two groups, Out of 88 patients 49(55.68\%) patients underwent Laparoscopic mesh repair [Group A] and 39(44.32\%) patients underwent open mesh repair. There were no significant differences between the age and sex ration between the two groups.Out of 88 patients 49 (55.68\%) patients underwent Laparoscopic mesh repair [Group A] and 39 (44.32\%) patients underwent open mesh repair.

Duration of surgery is relatively less in Group B Use of Drains, Complications like wound infection, seroma and haematoma is significantly less in Group A, Duration of hospital stay is relatively less in Group A, Return to normal activity is faster in Group A and stastically significant $(\mathrm{p}=0.04)$. 
Table-1: Demographic DATA.

\begin{tabular}{|c|c|}
\hline Total no of cases & 88 \\
\hline Age (years) & $42.7 \pm 8.2$ \\
\hline Male : Female & $59(67.05 \%): 29(32.95 \%)$ \\
\hline
\end{tabular}

Table-2: Demographic and operative results- comparison between the groups.

\begin{tabular}{|c|c|c|}
\hline & Group A & Group B \\
\hline Total no of cases & 49 & 39 \\
\hline Age & $40.6 \pm 7.7$ & $45.3 \pm 8.1$ \\
\hline Male: Female & $28(57.14 \%): 21(42.86 \%)$ & $31(79.49 \%): 8(20.51 \%)$ \\
\hline Duration of surgery(minutes) & $51.03 \pm 17.63$ & $50.51 \pm 9.85$ \\
\hline Use of Drains & $8(16.3 \%)$ & $19(48.71 \%)$ \\
\hline Complications & $3(6.1 \%)$ & $14(35.9 \%)$ \\
\hline Duration of hospital stay(days) & $4.14 \pm 0.65$ & $5.9 \pm 1.08$ \\
\hline Return to normal activity(weeks) & $3.2 \pm 0.7$ & $6.8 \pm 0.5$ \\
\hline
\end{tabular}

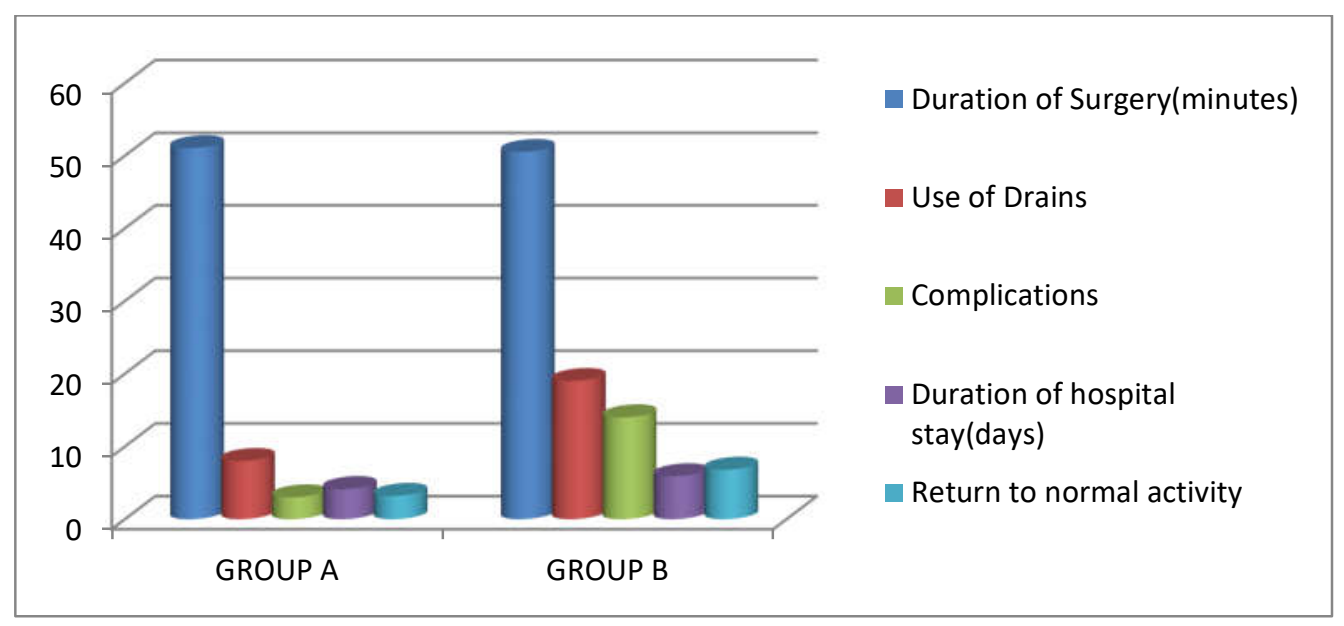

Figure-1

\section{Discussion}

Umbilical hernias generally develop from small fascial defects. Because of their size, a common practice is to repair the defect with primary sutures with the patient under local anaesthesia with sedation on an outpatient basis. Recurrence rates of up to $15 \%$ have been associated with this technique [8]. This was corroborated in a recent met analysis by van't Riet et alin which they reported similar incidences of hernia recurrence after repair with slowly absorbable and nonabsorbable sutures.

However, more wound pain and more suture sinuses occurred after the use of nonabsorbable sutures. They also reported similar outcomes between continuous and interrupted sutures.
In the laparoscopic technique, the mesh is placed in an intraperitoneal location and less often in the preperitoneal location, where the rise in the intra-abdominal pressures is totally diffused along each square inch of the mesh and not along a tenuous suture line, as happens in conventional suture repairs.

An increase in the intra-abdominal pressures thus helps to keep the mesh in place rather than displace it, as is the case in conventional overlay repairs. The laparoscopic approach affords the surgeon the ability to clearly and definitively define the margins of the hernia defect and to identify additional defects that may not have been clinically apparent preoperatively. Introduction of prosthetic mesh use in the umbilical hernia repair has 


\section{Original Research Article}

reduced the recurrences. The laparoscopic technique for ventral and incisional hernia repairs has resulted in decreased postoperative pain and duration of hospital stay, shorter return to normal activity, and lower recurrence rates [9]. The use of a variety of mesh materials for the repair of these hernias has resulted in a decreased recurrence rate when compared with that in primary suture closure. A prospective randomized trial has recently reported similar results for umbilical hernia repairs, with $11 \%$ versus $1 \%$ recurrence rates after primary suture and repair with mesh, respectively.

Laparoscopic umbilical hernia repair has been practiced since late 1990s [10,11] Today the utilization of laparoscopy for umbilical hernia repair remains relatively low in the world. Laparoscopy is preferred in just a quarter of the cases [12]. There are a few studies comparing open and laparoscopic repairs for umbilical hernias. Short-term outcomes from the American College of Surgeons National Surgery Quality Improvement Program recently revealed a potential decrease in the total and wound morbidity associated with laparoscopic repair for elective primary umbilical hernia repairs at the expense of longer operative time and length of hospital stay and increased respiratory and cardiac complications [13]. Choice of mesh appears to be more important for laparoscopic repairs [14].

Some authors argue that the use of tacks significantly reduces postoperative pain. Pain is generally worse after repair with sutures than with tacks. Sutures penetrate through the full thickness of abdominal wall musculature and fascia. This has been theorized to cause local muscle ischemia resulting in severe pain postoperatively [13]. Cobb et al. [14] has also proposed that intercostal nerves may become entrapped within the transabdominal sutures causing chronic, persistent neuropathic pain. Series of repairs using transfascial sutures report persistent pain and discomfort in $1 \%$ to $6 \%$ of patients [15]. None of our patient presented with persistent pain beyond 6 months.

Composite meshes are preferred materials in most institutions to avoid the risk of visceral adhesion into the mesh [15, 16] and laparoscopic also allows for identification of previously undiagnosed more hernia defects if any. In a recent series, laparoscopic umbilical hernia repair using a dual-layer polypropylene mesh and transfascial sutures significantly reduced surgical site infections, length of hospital stay, and costs as compared to open mesh repair. However, types of mesh used and fixation device can make sizeable differences in cost calculations. We used Trans abdominal suture for fixation of mesh with closure of umbilical defect in comparison to tackers to reduce the cost of procedure.

\section{Conclusion}

Laparoscopic umbilical hernia repair is a safe and effective technique with most of patients requiring less than 3 days of hospitalization, less use of drains, less complications, relatively equal surgery duration, early return to normal activity, laparoscopic surgery also helps in identification of undiagnosed more hernia defects.

Conflict of interest: None declared.

Funding: Nil, Permission from IRB: Yes

\section{References}

1. Seymour NE, Bell RL Brunicardi FC, Andersen DK, Billiar RT, Dunn DL, Hunter JG, Matthews JB, Abdominal wall, Omentum, Mesentry and Retroperitoneum. Schwartz's principles of surgery. $10^{\text {th }}$ edition. New York: McGraw-Hill; 2015: 1455.

2. Mayo WJ. VI. An Operation for the Radical Cure of Umbilical Hernia. Ann Surg. 1901 Aug;34(2):276-80.

3. Hesselink VJ, Luijendijk RW, de Witt JHW, Heide R, Jeekel J. An evaluation of risk factors in incisional hernia recurrence. SurgGynecol Obstet. 1993;176:228-234.

4. Stoppa RE. The treatment of complicatedgroin and incisional hernias. World J Surg.1989Sep-Oct;13(5):545-54.

5. Luijendijk RW, Hop WC, van den TolMP, de Lange DC, Braaksma MM, IJzermans JN, Boelhouwer RU, de Vries BC, Salu MK, Wereldsma JC, Bruijninckx CM, Jeekel J. A comparison of suturerepair with meshrepair for incisional hernia. N Engl J Med. 2000 Aug 10; 343(6):392-8.

6. Morris-Stiff GJ, Hughes LE. The outcomes of nonabsorbablemeshplaced within the abdominal cavity: literature review and clinical experience. J Am Coll Surg. 1998 Mar;186(3):352-67.

7. Jagad RB.Laparoscopic ventral hernia repair: a new method for fixation of the mesh with sutures. Surg Laparosc Endosc Percutan Tech. 2008 Jun;18(3):277-9. doi: 10.1097/SLE.0b013e31816aa12b.

8. García-Ureña MA, Rico P, Seoane J. Hernia umbilical Del adulto. Cirugía Española. 1994;56:302-306.

9. Ramshaw BJ, Esartia P, Schwab J, Mason EM, Wilson RA, Duncan TD, Miller J, Lucas GW, Promes J. Comparison of laparoscopic and open ventral herniorrhaphy.AmSurg.1999Sep;65(9):827-31; discussion 831-2. 


\section{Original Research Article}

10. Franklin ME, Dorman JP, Glass JL, Balli JE, Gonzalez JJ. Laparoscopic ventral and incisional hernia repair. SurgLaparoscEndosc. 1998 Aug;8(4):294-9.

11. Nguyen NT, Lee SL, Mayer KL, Furdui GL, Ho HS. Laparoscopic umbilical herniorrhaphy.J Laparoendosc Adv Surg Tech A. 2000 Jun;10(3):151-3.

12. Funk LM, Perry KA, Narula VK, Mikami DJ, Melvin WS. Current national practice patterns for inpatient management of ventral abdominal wall hernia in the United States. SurgEndosc. 2013 Nov;27(11):4104-12. doi: 10.1007/s00464-013-3075-4. Epub 2013 Jul 17.

13. Cassie S, Okrainec A, Saleh F, Quereshy FS, Jackson TD. Laparoscopic versus open elective repair of primary umbilical hernias: short-term outcomes from the American College of Surgeons National Surgery Quality
Improvement Program. SurgEndosc. 2014 Mar;28(3):7416. doi: 10.1007/s00464-013-3252-5. Epub 2013 Oct 26.

14. Eriksen JR, Gögenur I, Rosenberg J. Choice of mesh for laparoscopic ventral hernia repair. Hernia. 2007 Dec; 11 (6):481-92. Epub 2007 Sep 11

15. Nardi MJ, Millo P, BrachetContul R, Fabozzi M, Persico F, Roveroni M. Laparoscopic incisional and ventral hernia repair (LIVHR) with PARIETEX ${ }^{\mathrm{TM}}$ Composite mesh. Minim Invasive Ther Allied Technol 2012; 21: 173-180.

16. Tollens T, Struyve D, Aelvoet C, Vanrijkel JP. Introducing the Proceed Ventral Patch as a new device in surgical management of umbilical and small ventral hernias: preliminary results. SurgTechnol Int. 2010 Apr;19:99-103.

\section{How to cite this article?}

Abhinava D.M, Shashidhara Naik C, Seshagiri Rao K, Santhosh C.S, Mallikarjuna N Manangi, Niranjan Nagaraj. A clinical study of laparoscopic versus open umbilical hernia repair. Surgical Update: Int J surg Orthopedics.2017;3(4):157-161.doi:10. 17511/ijoso.2017.i04.11. 